\title{
Análise de questões avaliativas de fisiologia vegetal realizadas em um ambiente virtual de aprendizagem
}

Bruno Edson Chaves bruno.edson@uece.br 0000-0001-6031-5336 Universidade Estadual do Ceará, Iguatu, Ceará.

Lydia Dayanne Maia Pantoja Iydia.pantoja@uece.br 0000-0002-4446-7230 Universidade Estadual do Ceará, Fortaleza, Ceará

Rafael Domingos de Oliveira rafaeldomingos99@yahoo.com.br 0000-0003-2759-6740 Universidade Federal do Rio Grande do Norte, Natal, Rio Grande do Norte.

Roselita Maria de Souza Mendes roselita.mendes@uece.br 0000-0003-0705-2914 Universidade Estadual do Ceará, Fortaleza, Ceará

Germana Costa Paixão germana.paixao@uece.br 0000-0003-3232-8863 Universidade Estadual do Ceará Fortaleza, Ceará

\section{RESUMO}

A pesquisa através de parâmetros quantitativos analisou estatisticamente o desempenho de alunos frente às variadas formas de questões avaliativas e suas correlações que compuseram provas da disciplina de Fisiologia Vegetal aplicadas em seis turmas do Curso de Ciências Biológicas à distância da Universidade Estadual do Ceará/Universidade Aberta do Brasil - UECE/UAB. Para tanto, em um banco de 414 questões, foram avaliadas: tempo total de realização de prova, nota total da prova, tipo de formulação da questão, contextualização do enunciado, presença de elementos de ilustração, nível presumido de dificuldade e nota adquirida pelo aluno na questão específica. Constatou-se que o tempo de duração da prova não teve relação com as notas dos alunos e que o nível de dificuldade da questão é fator importante para os acertos, bem como, que a contextualização dos enunciados e presença de elementos ilustrativos nas questões não influenciou nas notas. Essa experiência tem possibilitado reflexões a respeito do processo avaliativo no curso.

PALAVRAS-CHAVE: Avaliação educacional. Educação a distância. Educação superior. 


\section{INTRODUÇÃO}

A avaliação é um processo complexo e dinâmico, sendo um "componente indissociável do ciclo constituído pelo ensino e pela aprendizagem", como afirma Fernandes (2004, p. 2), constituindo em elemento fundamental para o desenvolvimento dos sistemas educativos.

Um dos primeiros teóricos a propor o modelo tecnicista de avaliação foi Tyler (1949), que acreditava que a avaliação educacional era uma comparação entre os desempenhos dos alunos e os objetivos, definidos previamente. Posteriormente, no trabalho intitulado Manual de Avaliação Formativa e Somativa do Aprendizado Escolar (BLOOM; HASTINGS; MADAUS, 1971), os autores sugerem três funções para a avaliação: diagnóstica, formativa e somativa. Para Caldeira (2004, p. 4):

A avaliação formativa é a que ocorre ao longo do processo de aprendizagem. Seu objetivo é a correção de falhas do processo educacional e a prescrição de medidas alternativas de recuperação das falhas de aprendizagem. A avaliação somativa ocorre ao final de um processo, com claros objetivos de mensuração de resultados. Por fim a avaliação diagnóstica, que ocorre antes e durante o processo de aprendizagem, visando agrupar alunos de acordo com suas dificuldades no primeiro momento, e no final, identificar se houve, ou não, progresso em relação à assimilação dos conteúdos.

Entretanto, historicamente, embora os modelos de avaliação tenham se aperfeiçoado, foram marcados inicialmente pela avaliação como medida, com a aplicação dos chamados testes de inteligência e "em termos de sala de aula, a avaliação reduziu-se a função somativa, classificatória, seletiva, descontextualizada, padronizada (médias), com pouca participação dos alunos no processo" (OLIVEIRA, 2015, p. 19).

$\mathrm{Na}$ atualidade, busca-se priorizar avaliação como negociação e como construção, que tem "função formativa proeminente e corrobora para melhorar, desenvolver, aprender e motivar o aluno. Serve mais para ajudar na aprendizagem que para julgar ou classificar" (OLIVEIRA, 2015, p. 19). Nesse modelo de educação o feedback torna-se indispensável.

Logo, o processo avaliativo configura-se como instrumento indispensável à verificação do aprendizado realizado pelo aluno e concomitantemente, fornece contribuições ao trabalho docente, direcionando a melhoria do processo de ensino e aprendizagem dentro da disciplina. Frente ao tema, Haydt (1997, p. 7) considera que:

\footnotetext{
É importante verificar e julgar o rendimento dos alunos, avaliando os resultados do ensino. Há, também, aquelas que retêm e aplicam melhor o que lhes é ensinado. Cabe ao professor reconhecer as diferenças na capacidade de aprender dos alunos. Para poder ajudá-los a superar suas dificuldades e avançar na aprendizagem [...]. A forma como a avaliação é conduzida é um dos pontos mais críticos do ensino aprendizagem, o uso de seus resultados é ponto chave para qualquer avanço no desenvolvimento dos docentes e discentes.
}

Paralelamente, com o uso cada vez mais abrangente da internet, a educação a distância (EaD) assume relevância no ensino superior por meio do uso intensivo de tecnologias que possibilita o monitoramento do processo de ensino e aprendizagem (BENFATTI; STANO, 2010). Assim, com o dinamismo das tecnologias digitais de informação e comunicação, a EaD também vem priorizando um 
processo avaliativo dinâmico e diversificado, pois conforme Silva e Silva (2009) as questões avaliativas em EaD são fundamentais para futuras práticas dessa modalidade de ensino e para o próprio tema "avaliação".

Souza e Menezes (2014) fazem uma reflexão teórica sobre as principais concepções e possibilidades de avaliação relacionadas à EaD, considerando as especificidades dessa modalidade de ensino, os mesmos afirmam que:

Na educação, novos discursos e práticas são incorporados, provocando mudanças significativas no processo de ensino-aprendizagem e na concepção de sistemas de avaliação pedagógica. Os métodos avaliativos tradicionais, que enfatizam a supremacia do saber acumulado ao invés do conhecimento (re) construído pelo aluno, são progressivamente substituídos por outras abordagens mais focadas no desenvolvimento de habilidades e competências do aprendiz... (p. 159). [...] Evidentemente, a avaliação na EaD deve refletir essas especificidades e servir como um instrumento facilitador do processo de aprendizagem. Portanto, não basta apenas conceber mecanismos sofisticados de verificação da aprendizagem, é preciso que eles possuam como objetivos centrais o aperfeiçoamento contínuo, a construção do conhecimento e o desenvolvimento de novas competências (gerais e específicas) pelos educandos... (p. 168).

No momento presente, a avaliação ganha proporções maiores e novas respostas podem ser dadas diante de um processo avaliativo, surgindo novos conceitos, modelos, resultados e interpretações inovadoras (ANDRADE; TAVARES; VALLE, 2000), visto que avaliar nunca foi e jamais será tarefa fácil.

A partir dessas inquietações, os professores formadores e tutores do Curso de graduação em Ciências Biológicas a distância-BIOEAD da Universidade Estadual do Ceará/Universidade Aberta do Brasil-UECE/UAB resolveram investir na elaboração de bancos de questões para as diferentes disciplinas do curso, pautando-se em referenciais internos produzidos pela equipe de coordenação do curso, buscando produzir itens de avaliação diversificados e que pudessem ser aplicados aos alunos de forma randômica com o uso da ferramenta questionário disponível no ambiente virtual de aprendizagem Moodle. Essa experiência possibilitou reflexões a respeito do processo avaliativo, frente a estrutura concepcional, técnica e textual das questões bem como da mensuração de conhecimentos pretendidos como objetivo das avaliações aplicadas em diferentes turmas.

Nesse ínterim, o trabalho objetivou analisar por meio de diferentes parâmetros quantitativos o desempenho dos alunos frente às variadas formas de questões avaliativas e suas correlações que compuseram provas da disciplina de Fisiologia vegetal aplicadas em seis turmas do Curso de Graduação em Ciências Biológicas a distância da Universidade Estadual do Ceará/Universidade Aberta do Brasil-UECE/UAB.

\section{METODOLOGIA}

\section{Obtenção dos dados}

Trata-se de pesquisa de natureza quantitativa, que recorreu a linguagem matemática para descrever as bases de um fenômeno, as relações entre as 
variáveis (FONSECA, 2002). Assim, focou na mensuração de fenômenos, envolvendo a coleta e análise de dados numéricos e aplicação de testes estatísticos, para então chegar às conclusões correspondentes aos dados coletados (SILVA; KARKOTLI, 2011).

O estudo foi desenvolvido em seis turmas do Curso de Ciências Biológicas a distância da Universidade Estadual do Ceará/Universidade Aberta do Brasil UECE/UAB que cursaram a disciplina de Fisiologia vegetal, em quatro polos de apoio presencial (Aracoiaba, Beberibe, Itapipoca e Maranguape, todos no estado do Ceará), no período de 2009, 2010 e 2012 (Tabela 1). Participaram deste estudo 126 alunos, que realizaram 191 provas, divididas em provas parciais e provas finais da disciplina, disponibilizadas de forma online com o auxílio do ambiente virtual de aprendizagem Moodle 2.7.

Tabela 1 - Número de alunos / provas avaliadas* por polo e ano da turma. As turmas em que não apresentam dados de provas devem-se a não terem tido chamada pública para o vestibular.

\begin{tabular}{ccccc}
\hline Polos & Ano 2009 & Ano 2010 & Ano 2012 & TOTAL \\
\hline Aracoiaba & - & - & $24 / 39$ & $24 / 39$ \\
Beberibe & $14 / 19$ & $26 / 36$ & $30 / 44$ & $70 / 99$ \\
Itapipoca & $19 / 28$ & - & - & $19 / 28$ \\
Maranguape & - & - & $13 / 25$ & $13 / 25$ \\
Total & $33 / 47$ & $26 / 36$ & $67 / 108$ & $126 / 191$
\end{tabular}

* Para cada aluno foram analisadas a NPC (Nota Parcial de Conhecimento) da disciplina e a NEF (Nota de Exame Final), esta última só era realizada caso o aluno não atingisse a média (nota 7,0$)$ na NPC, requisito para passar direto na disciplina.

Os bancos de questões foram elaborados de forma colaborativa entre professores formadores e tutores em três momentos distintos para aplicação entre os alunos das turmas de 2009, 2010 e 2012, contendo respectivamente, 100, 160 e 154 questões, totalizando 414 questões. O número de perguntas elaboradas em cada banco de questões foi de pelo menos 3,5 vezes ao número de alunos por semestre, para minimizar a repetição de questões em diferentes provas, uma vez que cada prova era gerada de forma randômica do banco de questões a partir da ferramenta escolha disponível na plataforma.

\section{Elaborando os bancos de questões: estilos de questões e graduação de nível de dificuldade}

Os bancos contemplaram questões de 04 estilos de elaboração: múltipla escolha, verdadeiro ou falso, preenchimento de lacunas e associação de coluna (Figura 1), englobando, de forma o mais equânime possível, todos os conteúdos ministrados na disciplina de Fisiologia vegetal, tais como relações hídricas, nutrição mineral, fotossíntese, respiração, translocação do floema, hormônios vegetais, desenvolvimento vegetal e germinação.

Cada questão foi graduada de forma presumida pelo elaborador em três níveis de dificuldade: fácil, média e difícil. A definição do nível de dificuldade de cada questão baseou-se em critérios estabelecidos pelo núcleo gestor do Curso, que possui diretrizes internas de elaboração de questões de avaliação, baseando-se 
livremente nos critérios do Instituto Nacional de Estudos e Pesquisas Educacionais Anísio Teixeira (INEP) para elaboração de itens (BRASIL, 2010).

Foram classificadas como questões fáceis as que tinham enunciados fechados, envolvendo operações básicas de identificação, descrição e memorização direta de conceitos trabalhados em sala de aula e cuja temática estava explícita no livro-texto utilizado na disciplina. As questões de nível médio envolviam em seu enunciado mais de um conceito teórico e exigiam que o aluno trabalhasse conceitos de diferenciação, dissociação, estabelecendo conexão entre esses conceitos para chegar à resposta correta. Por fim, as questões graduadas como de nível difícil apresentaram múltiplos conceitos associados para chegar à resposta, onde o discente deve fazer análises complexas, relacionando pressupostos, evidências e hipóteses agregadas à interpretação de gráficos, tabelas e/ou figuras (CARDONA; AZAMBUJA; SANTOS, 2011; BRASIL, 2012).

Figura 1 - Exemplos das questões elaboradas. Na questão 01, observa-se uma questão de múltipla escolha, "fácil”, não contextualizada e que apresenta ilustração. Na questão 02, uma questão de coluna, "difícil", contextualizada e que não apresenta ilustração. A 3a questão refere-se a uma questão do tipo lacuna, com nível de dificuldade "médio", contextualizada e sem ilustração. Por fim, a 4ạ questão é do tipo verdadeiro ou falso, do nível de dificuldade "fácil", não contextualizada e sem ilustração. Os assuntos apresentados nas questões foram: fotossíntese, relações hídricas, desenvolvimento vegetal e respiração, para a 1ạ, 2a $3 \underline{a}$ e 4ạ questões, respectivamente.

\begin{abstract}
01. O processo fotossintético ocorre nos cloroplastos e é dividido em duas etapas: a fase clara e a fase escura. Assim, observando-se o esquema dado, é correto afirmar, EXCETO:
\end{abstract}

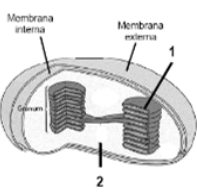

a) A fotólise da água ocorre em 2 .

b) A liberação de oxigênio ocorre em 1 .

c) A liberação de ATP e NADPH2 ocorre em 1 .

d) A utilização de água e de $\mathrm{CO} 2$ ocorre respectivamente em 1 e 2 .

03. As plantas apresentam capacidade de movimentação, reagindo a alguns estímulos do ambiente, através de movimentos de partes do seu corpo, como raizes, ramos, folhas ou flores. Ou seja, os vegetais recebem estímulos e são induzidos a respostas por meio de receptores que sofrem alterações e conduzem a mudanças metabólicas. A respeito destes processos indique a alternativa que preencha corretamente as lacunas do parágrafo abaixo.

"Tropismos são movimentos orientados em relação à fonte de estímulo, sendo que as respostas podem ocorrer na mesma direção, na direção oposta ou em ângulos específicos em relação ao estímulo. As respostas trópicas parecem estar relacionadas com a redistribuição lateral das _. São exemplos deste tipo de movimentos o em que a luz direciona a direção do movimento. Os caules tendem a crescer graças ao alongamento celular provocado pelas auxinas, na região menos iluminada da planta, fazendo com que se curva em direção ao estímulo. Outro tipo é o_em que o crescimento em resposta a um toque. Possibilita o crescimento de raizes em torno de rochas e a ascensão de trepadeiras ao redor de estruturas de suporte. É comum em gavinhas de chuchu e outras cucurbitáceas e em videiras."

a) Auxinas - Fototropismo - Gravitropismo

b) Giberelinas - Fotonastismo - Gravinastismo

c) Auxinas - Fototropismo - Tigmotropismos

d) Giberelinas - Fotonastismo - Tigmonastismo
02. O estresse é, na maior parte das definições, um desvi significativo das condições ideais para a vida, o que origin mudanças e respostas a todos os níveis do organismo. Esta respostas são inicialmente reversíveis, mas podem tornar-s irreversíveis, podendo ou não afetar a atividade fotossintética Desta forma, relacione o mecanismo de resistência a seca (Colun 2) e seu efeito na atividade fotossintética (Coluna 1). Note que ur elemento pode se associar mais uma vez.

Coluna 1

Coluna 2

$\begin{array}{lll}\text { 1- Afeta a } & \text { ( ) } & \begin{array}{l}\text { Plasticidade de desenvolvimento. } \\ \text { fotossintese }\end{array} \\ \text { 2- ( ) Não afeta a } & \text { ( ) } \begin{array}{l}\text { Tolerância à dessecação. } \\ \text { Redução da quantidade de radiação } \\ \text { fotossintese }\end{array} \\ & \text { ( ) } \begin{array}{l}\text { Redução da área do vegetal mais } \\ \text { sujeita a evaporação. } \\ \text { Manutenção da pressão de } \\ \text { turgescência (ajustamento osmótico } \\ \text { e/ou aumento da elasticidade da } \\ \text { parede celular). } \\ \text { Redução na resistência ao fluxo de } \\ \text { água do solo para as folhas. }\end{array}\end{array}$

04. Diversos fatores podem afetar as taxas respiratórias, a est respeito responda verdadeiro (V) ou falso (F) para os itens que s seguem.

( ) Redução na disponibilidade de substrato reduz a tax respiratória

( ) A necessidade de oxigênio varia de acordo com a espécie । com os diferentes órgãos da planta.

( ) Até $50^{\circ} \mathrm{C}$ ocorre elevação da taxa respiratória.

( ) Ataque de microrganismos promove acréscimo da tax respiratória

( ) Após danos mecânicos ocorre redução no consumo de $\mathrm{O}_{2}$ 
Para cada questão, os elaboradores indicavam a resposta correta (gabarito) e comentários consubstanciados que justificassem a resposta correta e explicasse os demais distratores.

As questões eram respondidas por meio da ferramenta questionário, disponível no Ambiente Virtual de Aprendizagem - AVA Moodle 2.7. As provas de turmas de mesmo semestre alocadas em polos de apoio presencial diferentes eram realizadas ao mesmo tempo para evitar troca de informações entre os alunos. A aplicação foi obrigatoriamente de forma presencial online, fiscalizadas por tutores, mediante liberação das questões por meio de senhas de acesso e respondidas sem o auxílio de nenhuma fonte de consulta.

Após a liberação do acesso, cada aluno entrava no seu questionário/prova, o qual selecionava, de forma randômica, dez questões do banco proposto para a disciplina naquele semestre. No final da prova o sistema fornecia o tempo total de realização da mesma, a nota total do aluno e a nota individual de cada questão resolvida, bem como mostrava o gabarito e comentário de cada questão fornecido pelo professor formador no ato da elaboração da questão, caracterizando-se num rico momento para aprendizado e correção de conceitos apreendidos de forma incorreta.

Logo, foram avaliadas as seguintes variáveis de cada prova: tempo total de realização de prova e nota total da prova ( $\mathrm{n}=191$, para cada uma das variáveis); assim como, para cada questão resolvida pelos alunos, foi possível analisar os dados: o tipo, a contextualização, a presença de ilustração, o nível de dificuldade e nota adquirida pelo aluno na questão específica. Uma vez que foram avaliadas 191 provas e cada prova continha 10 questões (proveniente da combinação de questões do banco de questões proposta para as turmas de cada ano), ao final do processo foram avaliadas 1.910 questões.

\section{Análise estatística}

Para verificar se o tempo de duração da prova estava relacionado com a nota final da avaliação foi realizada análise de regressão linear simples. A distribuição do tempo e das notas de provas foi verificada por meio da análise de distribuição Stem and Leaf. Com base na literatura, o gráfico que surge organiza em ordem crescente e separa cada valor em dois componentes, o caule (stem), formado por todos os valores da variável, exceção do último à direita, que corresponde à folha (leaf) (AYRES et al., 2012). Assim, diz-se que tal análise identifica um valor típico ou representativo (stem), a extensão da dispersão (leaf) ao redor do valor típico, bem como a extensão da simetria na distribuição dos valores (DEVORE, 2006) e, uma vez que preserva o valor de cada unidade, tal análise é vista melhor que os histogramas (AYRES et al., 2012).

Uma vez que o sistema fornecia a nota individual de cada questão e tinha-se acesso às demais informações (tipo de questão, contextualização, ilustração e nível de dificuldade) pela plataforma Moodle 2.7 e banco de questões de cada semestre, foi analisada a variação da nota individual de cada questão de acordo com o tipo, a contextualização, a presença de ilustração e o nível de dificuldade das questões.

Para analisar a relação entre o número de acertos com o nível de dificuldade individuais de cada uma destas categorias, em seguida, para comparação entre os 
níveis, foi realizada uma análise de variância (ANOVA) e, quando a diferença foi significativa, as suas médias foram comparadas pelo teste de Tukey a $5 \%$ de probabilidade (SANTOS et al., 2008). Procedimento semelhante também foi efetuado para comparar os acertos entre os tipos de questão.

Para averiguar o efeito da contextualização e da ilustração sobre a taxa de acerto, utilizou-se o teste $Z$. Este teste é semelhante ao teste $t$, sendo indicado quando a variância da população é conhecida, independentemente do tamanho da amostra. Vale ressaltar que se o $\mathrm{n}$ amostral for superior a 30 unidades (como é o caso do estudo) é dispensável pressupor a normalidade dos dados (AYRES, 2012).

Para verificar a influência da quantidade de questões de diferentes tipos sobre a nota e o tempo total da prova foi realizada uma análise de regressão linear múltipla. Tal análise considera a relação entre duas ou mais variáveis, neste caso cada um dos tipos de questão, com outra variável, que pode ser: nota total ou tempo de duração da prova (AYRES, 2012). Esta mesma análise foi utilizada para averiguar se a quantidade de questões de diferentes níveis interferiria na nota total da prova ou no tempo total da mesma.

Utilizando a nota individual de cada questão foi efetuada uma ANOVA fatorial para comparar cada um dos níveis de dificuldade das questões com outro critério, como: a contextualização, tipo de questão e ilustração. Assim, pode-se dizer se dentro de cada um destes critérios havia diferenças estatísticas entre os níveis de dificuldade ou se dentro de um mesmo nível de dificuldade haveria diferença estatística dentro do critério: presença ou não de contextualização, presença ou não de ilustração e os diferentes tipos de questão.

Todas as análises estatísticas supracitadas foram efetuadas no programa BioEstat 5.0 (AYRES et al., 2007).

\section{RESULTADO E DISCUSSÃO}

O tempo médio de realização das provas foi de $59,04 \pm 26,09$ minutos, contudo este tempo ficou mais concentrado entre 30 e 69 minutos uma vez que tiveram 112 observações $(58,63 \%)$ neste intervalo de tempo (Tabela 2 ).

A plataforma Moodle 2.7, assim como alguns outros sistemas, visa auxiliar o educador a aprimorar as suas aulas virtuais e avaliações, uma vez que permite ao educador dados como: tempo médio utilizado pelos alunos para responder determinada prova, média de acertos ou erros dos alunos em determinada questão e média das provas, além de disponibilizar o feedback da questão após a conclusão da prova. Desta forma, o professor poderia identificar falhas no conteúdo disponibilizado para seus alunos e até mesmo questões mal formuladas ou provas de grau de dificuldade muito difícil para determinadas turmas (TORRES, 2009). Ainda de acordo com este autor, o tempo utilizado para responder a prova inteira, também é considerado um dado estatístico que deve ficar à disposição do professor para refinamento de seu material.

A média das notas foi de $63,10 \pm 17,38$ pontos, com destaque para as concentrações de notas entre 5,0 e 7,8 resultado de $58,11 \%$ das provas, ou seja, 191 provas avaliadas (Tabela 3 ). 
Tabela 2 - Distribuição dos tempos de realização da prova pelo teste estatístico Stem and leaf.

\begin{tabular}{clll}
\hline Escores $=191$ & Stem & Leaf \\
\hline 8 & 1 & 04456699 \\
12 & 2 & 122345667888 \\
28 & 3 & 0000003334444455667777789999 \\
26 & 4 & 01111122234455666677778899 \\
28 & 5 & 0011122222333444555677888888 \\
30 & 6 & 000000111111244555555577888889 \\
21 & 7 & 001133333444456788999 \\
17 & 8 & 00011133333344677 \\
6 & 9 & 000556 \\
5 & 10 & 05589 \\
3 & 11 & 126 \\
4 & 12 & 0238 \\
2 & 13 & 13 \\
1 & 14 & 4 \\
& &
\end{tabular}

Tabela 3 - Distribuição das notas da prova pelo teste estatístico Stem and leaf.

\begin{tabular}{rlll}
\hline Escores = 191 & & Stem & Leaf \\
\hline 1 & 1 & 0 \\
4 & 2 & 0058 \\
10 & 3 & 0002446689 \\
25 & 4 & 0000000000122224445568899 \\
30 & 5 & 000000000000002234446666688899 \\
38 & 6 & 00000000000000012224444566666667888889 \\
43 & 7 & 000000000000000000112222222344445666667888 \\
29 & 8 & 00000000000000001144444666889 \\
10 & 9 & 0000244558 \\
1 & 10 & 0
\end{tabular}

No tocante especificamente às notas, a literatura reporta que a maioria dos estudantes universitários é dependente do resultado quantitativo, a nota propriamente dita, muitas vezes não se importando com o retorno do instrumento aplicado (ZANON; ALTHAUS, 2008), situação essa que o curso de Ciências Biológicas tenta contornar, quando solicita que cada questão preparada pelo professor/tutor tenha o gabarito e comentário referentes a todos os itens elaborados, apontando os possíveis erros, procurando intervir, discutir e proporcionar feedback para todos os alunos. O feedback que o aluno recebe após 
a realização da questão é proveniente dos comentários que foram adicionados às questões na hora de sua geração, e é por isso que é tão importante ambos terem acesso a essas informações (TORRES, 2009).

As análises indicam que o tempo de duração da prova não tem relação com as notas dos alunos ( $F=3,6665 ; G L=1 ; p=0,0539 ; R 2$ ajustado $=0,0142)$. Dados semelhantes foram ressaltados por Cornachione Júnior e Guerreiro (2007) para um curso de ensino superior na Universidade de São Paulo (USP). A concentração do tempo médio de duração da prova de um dos grupos avaliados pelos pesquisadores no curso da USP foi semelhante aos resultados obtidos nesse trabalho, entretanto, a concentração das notas obtidas por parte dos alunos do curso de Ciências Biológicas apresentadas aqui foi superior ao apresentado no trabalho supracitado, porém, vale destacar que as provas deste trabalho não foram feitas em ambiente Moodle.

Observou-se que o nível de dificuldade da questão influencia significativamente os acertos. Considerando que cada questão vale de 0 a 10 , as questões fáceis tiveram notas individuais médias de $6,71 \pm 4,45$, as questões de nível médio tiveram notas individuais médias de 6,22 $\pm 4,58$, e as questões consideradas com nível difícil 5,60 $\pm 4,45$. Estatisticamente $(F=6,935 ; G L=2 ; p=$ $0,0014)$ as questões fáceis foram semelhantes às de nível médio e estas semelhantes às difíceis; o nível fácil mostrou-se estatisticamente diferente das de nível difícil. Assim, observa-se que eles acertaram mais as questões de nível fácil e erraram mais as questões de nível difícil, como era esperado.

No tocante ao critério nível de dificuldade, os dados apresentados foram corroborados por estudo de Oliveira (2011), cujo objetivo foi realizar um estudo exploratório e descritivo, a fim de descrever a compreensão em leitura de estudantes universitários de diferentes estados brasileiros. Ao considerar a análise descritiva dos acertos com o julgamento da dificuldade, ficou evidente para o autor que a maior parte dos acertos apresentou concordância com o julgamento da dificuldade realizada por quem elaborou a questão, bem como, os itens considerados mais fáceis foram mais acertados pelos estudantes.

Em termos percentuais esta relação também foi observada. Ao todo, das 1.910 questões respondidas, 806 foram fáceis, 812 médias e 293 de nível difícil. Dentro de cada um destes grupos foram acertadas (acima de $80 \%$ da questão) 523 perguntas de nível fácil (64,88\% das perguntas deste nível de dificuldade), 474 questões de nível médio (58,37\%) e 145 questões de nível difícil $(49,48 \%)$.

Em um estudo realizado por Morgado et al. (2012), os autores também observam que independente dos assuntos relativos à pergunta, as questões mais fáceis tiveram um percentual de acerto maior que as ditas pelos autores como normais. Neste trabalho questões de nível médio tiveram um percentual de acerto maior que as ditas difíceis, corroborando, mais uma vez os dados apresentados nos quais o nível de dificuldade das questões avaliadas pode influenciar na taxa de acertos percentual das mesmas.

Foi avaliado ainda se a quantidade de questões fáceis, médios ou difíceis influenciariam no tempo total da prova ou na nota total da prova. Ou seja, esperava-se que uma prova que tivesse mais questões fáceis o aluno iria demorar menos tempo para resolvê-la e/ou ter uma nota melhor do que o aluno que resolvesse uma prova com mais questões difíceis. Para esta análise assim se aceita a hipótese nula de que a quantidade dos tipos de questões não influencia na nota 
$(F=1,1604 ; G L=3 ; p=0,3261 ; R 2$ ajustado $=0,0026)$ nem no tempo $(F=0,0861$; $\mathrm{GL}=3 ; \mathrm{p}=0,9667 ; \mathrm{R} 2$ ajustado $=0,0146$ ).

Assim como uma prova de vestibular, as provas no sistema Moodle 2.7 apresentam a mesma pontuação independente do nível de dificuldade. Neste contexto Wachelke e Botomé (2004) afirmam que a tendência é que os alunos estudem mais os assuntos que consideram fáceis e intermediários, uma vez que demandam menos tempo para serem dominados. Por outro lado, os assuntos considerados difíceis exigem muito tempo de estudo, mas tem mesma pontuação.

Assim, quando estão resolvendo uma pergunta da prova se ela for fácil provavelmente ele teria estudado bem aquele assunto e teria acertado rapidamente. Contudo, para as perguntas ditas difíceis há duas hipóteses: 1) os alunos demorariam mais para responder, pois estariam pensando mais em como responder aquela pergunta de forma satisfatória, contudo, devido ao grau de dificuldade, ele poderia acertar ou errar a pergunta mesmo que demore a responder; 2) por não ter estudado muito aquele assunto, os alunos não perdem muito tempo pensando na resposta e acabam selecionando qualquer opção aleatoriamente. Nesta hipótese, a seleção da alternativa ocorre de forma rápida, contudo a probabilidade do erro é maior que a do acerto. Tais hipóteses têm reflexos tanto em relação ao tempo de duração total da questão e de sua respectiva nota, o que pode influenciar o tempo total e a nota total da avaliação.

Com base nos resultados supramencionados da relação entre a dificuldade da questão e o tempo total de prova e nota total de prova, se aceita que nas questões difíceis e, talvez, em algumas questões ditas intermediárias, provavelmente, os alunos escolheram uma opção de forma aleatória. Neste caso, o tempo de duração da pergunta também seria rápido, semelhante às perguntas de nível fácil, mas o percentual de acerto seria baixo. Nota-se que as perguntas de nível difícil foram as que tiveram menor percentual de acertos.

No que se refere à contextualização das questões, observou-se que esta, de forma geral, não influencia nas notas das questões $(Z=0,2716 ; p=0,3930)$. Foi avaliada a interação entre a contextualização das questões e o nível das provas ( Tabela 4) e observou-se que não há interação entre estes dois critérios ( $F=0,8529$; $\mathrm{GL}=2,174 ; \mathrm{p}=0,5688)$, contudo observou-se diferença estatística significativa entre os níveis $(F=3,0463 ; G L=2,174 ; p=0,0486)$ e a contextualização $(F=4,8618$; $\mathrm{GL}=1,174 ; \mathrm{p}=0,03)$ das questões.

Tabela 4 - Relação entre a contextualização e o nível das questões.

\begin{tabular}{lccc}
\hline & Fácil & Médio & Difícil \\
\hline Sem contextualização & $6,79 \pm 4,59^{\text {a A }}$ & $6,24 \pm 4,63^{\text {ab A }}$ & $5,29 \pm 4,97^{\text {b A }}$ \\
Com contextualização & $6,60 \pm 4,26^{\text {a A }}$ & $6,20 \pm 4,53^{\text {a A }}$ & $5,88 \pm 3,93^{\text {a A }}$ \\
\hline
\end{tabular}

Nota: Médias seguidas pela mesma letra minúsculas (linhas) ou maiúsculas (colunas) não diferem estatisticamente pela ANOVA fatorial seguida do teste de Tukey ao nível de $5 \%$ de probabilidade.

A contextualização das questões são aspectos importantes, pois objetiva analisar o raciocínio do estudante de forma interdisciplinar e contextualizada em situações cotidianas. Com base nos processos avaliativos tradicionais, a saber:

[...] os processos avaliativos escolares no Brasil caracterizam-se por uma excessiva valorização da memória e dos conteúdos "em si", reforçando a crença segundo a qual conhecer é dispor de um repertório de respostas-padrão a 
problemas já conhecidos. A avaliação, neste contexto, é a simples constatação desse repertório (BRASIL, 2009, p. 9).

Assim pode-se dizer que, embora não haja relação entre as notas obtidas para as questões com e sem contextualização de forma mais ampla, quando são considerados os níveis de dificuldade, pode-se encontrar diferenças significativas, especialmente quando as questões não são contextualizadas (Tabela 4). Tais dados demostram que avaliar a contextualização de uma questão deve ser feita com muito mais critério do que simplesmente verificar se a contextualização ou não da questão pode interferir na taxa de acerto da mesma. Quando analisada concomitante ao nível de dificuldade nota-se que, independente do nível, as questões contextualizadas apresentam, estatisticamente, o mesmo nível de dificuldade, podendo, assim, o aluno ter mais chances de acertar questões difíceis. Por outro lado, as questões sem contextualizações fáceis tiveram uma taxa de acerto maior que as questões difíceis, as questões de nível médio foram estatisticamente semelhantes às demais. Este resultado se assemelha ao encontrado quando analisado as taxas de acerto das questões por nível de dificuldade, demostrando que perguntas diretas e/ou não contextualizadas não oferecem subsídios para uma maior reflexão da questão assim o aluno tende a acertar, de fato, as mais fáceis e errar as mais difíceis.

Ao avaliar o tipo de questão notou-se que existe diferença significativa $(\mathrm{F}=$ 8,$9483 ; \mathrm{GL}=3 ; \mathrm{p}<0,0001$ ) entre a taxa de acerto para os diferentes tipos (múltipla escolha, preenchimento de lacuna, verdadeiro ou falso e associação de coluna) Tabela 5. As questões com maiores taxas de acertos foram as do tipo preenchimento de lacuna e verdadeiro ou falso, as com menores taxas foram às questões de múltipla escolha; as questões de associação de colunas foram estatisticamente semelhantes aos demais tipos, conforme mostra a coluna geral na Tabela 5.

Tabela 5 - Relação entre o tipo e o nível de dificuldade das questões.

\begin{tabular}{|c|c|c|c|c|}
\hline & Fácil & Médio & Difícil & Geral \\
\hline $\begin{array}{l}\text { Associação de } \\
\text { Coluna }\end{array}$ & $9,05 \pm 1,97$ a $\mathrm{A}$ & $\begin{array}{c}6,13 \pm 3,12^{a} \\
A B\end{array}$ & $\begin{array}{c}5,75 \pm 4,399^{a} \\
A B\end{array}$ & $6,63 \pm 3,64^{A B}$ \\
\hline $\begin{array}{l}\text { Preenchimento de } \\
\text { Lacuna }\end{array}$ & $6,94 \pm 4,62$ a $\mathrm{A}$ & $7,39 \pm 4,31^{\text {a } A}$ & $7,65 \pm 4,31$ a $A$ & $7,20 \pm 4,50^{B}$ \\
\hline Múltipla Escolha & $6,44 \pm 4,78$ a A & $\underset{B}{5,75 \pm 4,95}$ & $4,65 \pm 5,01$ b в & $5,91 \pm 4,91^{A}$ \\
\hline $\begin{array}{l}\text { Verdadeiro ou } \\
\text { Falso }\end{array}$ & $6,92 \pm 2,55^{\text {a A }}$ & $\frac{6,69 \pm 3,15^{a}}{A B}$ & $\begin{array}{c}6,34 \pm 2,899^{a} \\
A B\end{array}$ & $6,68 \pm 2,89^{B}$ \\
\hline
\end{tabular}

Nota: Médias seguidas pela mesma letra minúsculas (linhas) ou maiúsculas (colunas) não diferem estatisticamente pela ANOVA fatorial seguida do teste de Tukey ao nível de 5\% de probabilidade. Nota2: Os dados gerais referem-se as respostas de cada tipo de questão sem a separação entre os níveis. Neste caso usou-se ANOVA um fator, seguida do teste de Tukey ao nível de $5 \%$ de probabilidade. Médias seguidas pela mesma letra não diferem estatisticamente por esse teste.

O tipo de questão múltipla escolha é relatado na literatura como de complexa elaboração e definida como "aquelas que já trazem enunciadas as possibilidades de resposta entre as quais o aluno escolhe a única que responde corretamente ao problema proposto" (MINAS GERAIS, 2009, p. 14), logo, devido à complexidade da mesma, assemelha-se ao fato desse tipo de questão ter apresentado as menores taxas de acerto. 
O uso das questões do tipo lacuna e verdadeiro ou falso é interessante quando se quer avaliar um número significativo de conceitos e características (MINAS GERAIS, 2009), mostrando que as questões desse tipo foram bem assimiladas pelos alunos, já que foram as questões com maior taxa de acerto.

Para Melchior (1994) as perguntas do tipo preenchimento de lacuna apresentam menor possibilidade de acerto casual e possibilita uma avaliação rápida, contudo avalia apenas a capacidade de memorização e de compreensão do conteúdo do educando. Este mesmo trabalho ressalta que a grande vantagem das questões de verdadeiro ou falso é a abrangência de uma amostra significativa do conteúdo; entretanto, este tipo de questão é discutido na literatura, pois segundo Melchior (1999, p.105), "poucas são as vantagens no uso deste tipo de questão em testes escolares, mas são questões úteis para serem trabalhadas como exercícios, em sala de aula [...] entre as desvantagens do seu uso em testes, destaca-se a possibilidade de $50 \%$ de acerto casual".

No que se refere às questões de associação de colunas estas têm a vantagem de ter uma grande abrangência do conteúdo, porém apresenta duas importantes desvantagens: grande possibilidade de acerto casual e, na interligação entre os itens, um erro em uma das associações pode provocar o erro de outra (MELCHIOR, 1994). Possivelmente o fato deste tipo de pergunta ter tido valores intermediários na taxa de acerto deva-se a essa segunda desvantagem.

Também existe interação entre o tipo de questão e o nível de dificuldade das mesmas ( $F=2,2697 ; G L=6,348 ; p=0,0362)$, bem como entre o tipo de questão com os diferentes níveis de dificuldade $(F=3,1145 ; G L=2,348 ; p=0,0442)$ e também se considerarmos os diferentes tipos de questão no mesmo nível de dificuldade $(F=7,9141 ; G L=3,348 ; p=0,0001)$, como é observado na Tabela 5.

No tocante as questões de múltipla escolha, as que apresentaram nível de dificuldade fácil tiveram maiores acertos que as questões difíceis; as questões de nível médio foram estatisticamente iguais às demais. Isto não foi observado nos demais tipos de questões, uma vez que as questões do tipo associação de colunas, preenchimento de lacunas e verdadeiro ou falso não tiveram diferenças estatísticas significativas entre os níveis de dificuldade (Tabela 5).

Para as questões consideradas com nível de dificuldade difícil e médio os maiores e menores acertos ocorreram nas questões de preenchimento de lacuna e múltipla escolha, respectivamente. Os demais tipos foram estatisticamente iguais aos outros dois (associação de coluna e verdadeiro ou falso). Considerando somente as questões de nível fácil não houve diferença estatística significativa nas notas individuais das questões entre os tipos de questão (Tabela 5).

A questão de múltipla escolha é consagrada no Ensino Superior (SALINAS, 2004), sendo muito comum utilizar uma citação textual como iniciação para contextualizar este tipo de questão. Vale ressaltar que, quando os alunos questionam ao professor que "tipo" de prova será utilizado, é reportado na literatura que, quando o professor afirma ser de múltipla escolha, "o aluno poderá processar as informações de maneira mais ou menos superficial" (ZANON; ALTHAUS, 2008, p. 5), logo, esse pensamento pode justificar que as questões de múltipla escolha com nível fácil foram as com maior acerto.

Acrescenta-se ainda o fato de que questões de múltipla escolha diminuem o erro casual, assim como as de associação de lacuna, porém, diferente desta, 
permite maior interpretação, raciocínio dedutivo e indutivo e julgamento (MELCHIOR, 1994). Este tipo de questão, de certa forma, torna-se ligeiramente mais complexo que as de preenchimento de lacuna, o que é refletido na distribuição entre os diferentes níveis de dificuldade, bem como justifica o fato de que as questões de níveis médio e difícil foram as que tiveram menores taxas de acertos quando comparado com os demais tipos de perguntas, especialmente como o do tipo preenchimento de lacuna.

Ainda no que concerne aos tipos de questões, foi avaliado se a quantidade de como tais tipos influenciaria no tempo total da prova ou na nota total da prova. Observou-se que não há relação entre o número de cada um dos tipos de questão com o tempo de prova $(F=1,4159 ; G L=4 ; p=0,2292 ; R 2$ ajustado $=0,0087)$. Contudo, há relação com a nota da prova $(F=2,5189 ; G L=4 ; p=0,0422 ; R 2$ ajustado $=0,0318$ ). $O$ coeficiente parcial de regressão mostra que individualmente $(p=1.00)$ nenhum dos tipos de questões revela interação com a nota total da prova, entretanto, a comparação entre os coeficientes apresentados pelo tipo de questão lacuna e múltipla escolha $(p<0.0001)$ e lacuna e verdadeiro ou falso ( $p=$ 0.0391) mostram que quando há mais questões destes tipos, de forma proporcional, as notas tendem a serem maiores.

Para Trancredi (2002) a equitatividade dos tipos de questões e nível de dificuldade destas favorecem o desempenho dos alunos. Logo, ter uma relação entre, pelo menos, dois diferentes tipos de questão melhoraria o desempenho dos alunos. Nota-se que nos dois tipos de interação apresentadas, há a presença da questão do tipo lacuna, o qual teve elevada taxa de acerto conforme mostra a Tabela 5. Contudo dentre os dois tipos de interações propostas, acredita-se que a interação entre lacuna e verdadeiro ou falso seria mais recomendada, pois é justamente os tipos com maiores taxas de acertos entres os tipos de questões propostos (Tabela 5).

Em relação às ilustrações, notou-se que, para o banco de questões da disciplina avaliada, estas não influenciam na nota individual das questões ( $Z$ = 0,$6947 ; p=0,4872$ ). Foi avaliada a interação entre a ilustração das questões e o nível das provas (Tabela 6) e observou-se que não há interação entre estes dois critérios ( $F=0,0777 ; G L=2,42 ; p=0,9249)$, bem como entre os tratamentos: com e sem ilustração ( $F=3,44 ; G L=1,42 ; p=0,0673)$. Apesar disso, observou-se diferença estatística significativa nas notas individuais das questões entre os níveis de dificuldade $(F=3,7598 ; G L=2,42 ; p=0,0306)$, neste caso, quando não havia ilustração as perguntas de nível fácil tiveram notas individuais maiores $(6,68 \pm$ $4,46)$ que as de nível difícil $(5,63 \pm 4,42)$, as de nível médio $(6,18 \pm 4,59)$ mostraramse estatisticamente iguais as demais; não houve diferença estatística significativa nas notas individuais das questões entre os níveis de dificuldade nas questões com ilustração.

Tabela 6 - Relação entre a ilustração e o nível de dificuldade das questões.

\begin{tabular}{cccc}
\hline & Fácil & Médio & Difícil \\
\hline Sem ilustração & $6,68 \pm 4,46^{\text {a A }}$ & $6,18 \pm 4,59^{\text {ab A }}$ & $5,63 \pm 4,42^{\text {b A }}$ \\
Com ilustração & $9,25 \pm 2,12^{\text {a A }}$ & $6,76 \pm 4,43^{\text {a A }}$ & $5,00 \pm 5,18^{\text {a A }}$ \\
\hline
\end{tabular}

Nota: Médias seguidas pela mesma letra minúsculas (linhas) ou maiúsculas (colunas) não diferem estatisticamente pela ANOVA fatorial seguida do teste de Tukey ao nível de $5 \%$ de probabilidade. 
Para Ferraro (2012) as imagens e ilustrações, além de constituir um artifício pedagógico, são um importante recurso de comunicação, uma vez que são elementos que ajudam o leitor a compreender mais facilmente a mensagem que se deseja transmitir (TEODOROWITSCH, 2013). Assim, pode-se dizer que a presença de ilustração facilita a abstração da questão, ou seja, este recurso icônico colabora com a interpretação da questão, tornando-a mais assimilável e mais fácil de ser compreendida. Tanto que, quando não apresenta a figura, é possível que os alunos tenham dificuldade na abstração o que justificaria a diferença significativa entre o acerto nas questões de níveis fácil e difícil.

\section{CONSIDERAÇÕES FINAIS}

Essa experiência possibilitou reflexões a respeito do processo avaliativo dentro do curso de Ciências Biológicas a distância - UECE/UAB. Os dados analisados apontaram que frente ao banco de questões elaborado para a disciplina de Fisiologia vegetal e, posteriormente avaliado, o tempo de duração da prova não teve relação com as notas dos alunos. Foi observado que o nível de dificuldade da questão é um fator importante para os acertos; os resultados também apontam que para a elaboração de questões avaliativas é importante considerar a combinação entre o tipo e o nível de dificuldade das questões, de forma que o desempenho satisfatório dos alunos seja alcançado por meio da interação entre diferentes tipos de questões, especialmente entre lacuna e múltipla escolha e entre lacuna e verdadeiro ou falso, que tendem a abordar o conteúdo de forma mais ampla e favorecem o desempenho dos alunos.

Outro ponto importante apresentado foi que as contextualizações e a presença de ilustrações, não influenciaram na nota individual das questões.

Diante de tais observações, os resultados apontam que a ação de avaliar continua sendo complexa e dinâmica, logo estudos de análise de seus processos e de suas variáveis quantitativas, sob a ótica da estatística, são importantes para amadurecer o professor sobre o que é e qual a função da avaliação.

Por fim, os resultados apontam que deve ser estimulado o repensar da avaliação na universidade, em especial na modalidade a distância, onde questões avaliativas discutidas no presente trabalho são fundamentais para futuras práticas dessa modalidade de ensino e para o próprio tema avaliação. 


\title{
Analysis of evaluation questions about plant physiology performed in a virtual learning environment
}

\begin{abstract}
The research through quantitative parameters statistically analyzed the performance of students submitted to different kind of evaluative questions and their correlations, which composed exams of the Plant Physiology course given in six classes of distance learning undergraduate in Biological Sciences of the Universidade Estadual do Ceará/Universidade Aberta do Brasil - UECE/UAB. Therefore, within a bank of 414 questions, the following parameters were evaluated: total time of test execution, total grade of the exam, type of question, question contextualization, illustration presence, presumed level of difficulty and score achieved for each specific question. Results indicated no relation between the students' grades and the time of exam execution. The difficulty level of question is an important factor that drives to the right answers. However, question contextualization and presence of illustrations did not have influence on grades. This experience has given possibilities to reflex on the evaluative process of the undergraduate course.
\end{abstract}

Keywords: Educational evaluation. Distance learning education. Higher education. 


\section{REFERÊNCIAS}

ANDRADE, D.; TAVARES, H. R.; VALLE, R. C. Teoria da resposta ao item: conceitos e aplicações. São Paulo: Associação Brasileira de Estatística, 2000. 164 p.

AYRES, M. Elementos de bioestatística: a seiva do açaizeiro. 2. ed. Belém: lone Serra, 2012. 588 p.

AYRES, M.; AYRES, D. L.; AYRES, L. L.; SANTOS, B. A.; AYRES JR., M.; FURLANETO, I. P.; AMARAL, A. A. Pequeno dicionário de bioestatística. 3. ed. São Paulo: Embrapa Amazônia Oriental, 2012. 175 p.

AYRES, M.; AYRES JR., M.; AYRES, D. L.; SANTOS, A. A. S. Bioestat 5.0: aplicações estatísticas nas áreas das ciências biológicas e médicas. 5. ed. Belém: IDSM, MCT, CNPq, 2007. 364 p.

BATISTA, M. A. M. Avaliação: um intervir sobre a produção do conhecimento. Pensar a Prática, v. 3, n. 1, p. 65-71, 2000.

BENFATTI, E. F. S. S.; STANO, R. C. M. T. Utilização da tecnologia em educação a distância na formação de engenheiros de produção da Universidade Federal de Itajubá: uma avaliação educacional. Gestão \& Produção, v. 17, n. 2, p. 433-446, 2010.

BLOOM, B.; HASTINGS, J. T.; MADAUS, G. F. Manual de avaliação formativa e somativa do aprendizado escolar. São Paulo: Pioneira Editora, 1971.

BRASIL. Ministério da Educação. Exame nacional do ensino médio, textos teóricos e metodológicos. Brasília: MEC, SEB, Inep, 2009.

BRASIL. Ministério da Educação - MEC. Guia de livros didáticos - PNLD 2012: Física. Brasília: Ministério da Educação, Secretaria de Educação Básica, 2011. 90 p.

BRASIL. Instituto Nacional de Estudos e Pesquisas Educacionais Anísio Teixeira (INEP). Guia de Elaboração e Revisão de Itens. Vol. 1. Brasília, 2010.

CALDEIRA, A. C. M. Avaliação da aprendizagem em meios digitais: novos contextos. XI Congresso Internacional de Educação a Distância. Salvador, 2004. Disponível em: http://www.abed.org.br/congresso2004/por/htm/033-TC- 
CORNACHIONE JÚNIOR, E. B; GUERREIRO, R. Tempo de realização de prova e performance dos alunos: aspectos do processo de avaliação formal com base em instrumentos objetivos. BASE - Revista de Administração e Contabilidade da Unisinos, v. 4, n. 3, p. 223-232, 2007.

DEVORE, J. L. Probabilidade e estatística: para engenharia e ciências (Tradução Joaquim Pinheiro Nunes da Silva). São Paulo: Pioneira Thomson. Learning, 2006. $692 \mathrm{p}$.

CARDONA, A. V.; AZAMBUJA, C. R. J.; SANTOS, M. B. Enade comentado 2008: Matemática. Porto Alegre: EDIPUCRS, 2011. 121 p.

FERNANDES, D. Avaliação das aprendizagens: uma agenda, muitos desafios. Lisboa: Texto, 2004. 56 p.

FERRARO, J. R. Produção dos livros didáticos: uma reflexão sobre imagem, texto e autoria. Cadernos do CEOM - Arquivos e tecnologias digitais, v. 25, n. 34, p. 170-188, 2012.

FONSECA, J. J. S. Metodologia da pesquisa científica. Fortaleza: UECE, 2002. 127 p. Apostila.

HAYDT, R. C. Avaliação do processo ensino aprendizagem. São Paulo: Ática, 1997.

MELCHIOR, M. C. Avaliação pedagógica: função e necessidade. Porto Alegre: Mercado Aberto, 1994. 150 p.

MELCHIOR, M. C. Avaliação pedagógica: função e necessidade. 2. ed. Porto Alegre: Mercado Aberto, 1999. p. 75-125.

MINAS GERAIS. Secretaria de Estado de Educação. Guia de elaboração e revisão de questões e itens de múltipla escolha. 2009. 32 p.

MORGADO, F.; BARBOSA, N. M.; LACERDA, N. N. N.; RENAN, M. P. Análise estatística dos testes de progresso focando os cursos de Engenharia. In: Congresso Brasileiro de Educação em Engenharia, 40., 2012. Belém. Anais... Belém: UFPA, 2012. 21 p.

OLIVEIRA, D. M. Ensino a distância, avaliação online e cursos superiores de 
OLIVEIRA, K. L. Considerações acerca da compreensão em leitura no ensino superior. Psicologia: ciência e profissão, v. 31, n. 4, p. 690-701, 2011.

SALINAS, D. Prova amanhã: entre a teoria e a realidade. Porto Alegre: Artmed, 2004. 128 p.

SANTOS, J. W. dos; ALMEIDA, F. de A. C.; BELTRÃO, N. E. de M.; CAVALCANTI, F. B. Estatística experimental aplicada. 2. ed. Campina Grande: Embrapa Algodão, Universidade Federal de Campina Grande, 2008. 461 p.

SILVA, R.; KARKOTLI, G. (Orgs.). Manual de metodologia científica do USJ 2011-1. São José: Centro Universitário Municipal de São José - USJ, 2011. 99 p.

SILVA, Â. C.; SILVA, C. M. T. Do diagnóstico às questões avaliativas: um caminho possível via prática de avaliação em educação a distância. Ensaio: Avaliação e Políticas Públicas em Educação, v. 17, n. 63, p. 293-312, 2009.

SOUZA, T. E. S.; MENEZES, A. H. N. Avaliação em educação a distância: concepções e possibilidades. REVASF, Petrolina, PE, v. 4, n. 6, p. 158-170, 2014.

TANCREDI, R. M. S. P. O acompanhamento do processo ensino-aprendizagem através das provas escritas. 2002. Disponível em: $<$ http://www.dm.ufscar.br/.../pro.../ Metodos\%20de\%20Ensino/instrumentosavaliacao.pdf>. Acesso em: 06 jan. 2016.

TEODOROWITSCH, R. Manual de ética, estilo e português para a elaboração de trabalhos acadêmicos. 2003. Disponível em: <http://www.urisan.tche.br/ cspm/ Interessantes/manualdeelaboracao.pdf>. Acesso em: 06 jan. 2016.

TYLER, R. Basic principles of curriculum and instruction. Chicago: University of Chicago. 1949.

TORRES, D. O. Sistema de gerência de questões e respostas: avalweb ${ }^{\circledR} 2.0 .2009$. 56 f. Trabalho de graduação (Ciência da Computação) - Instituto de Informática, Universidade Federal do Rio Grande do Sul, Porto Alegre, 2009.

WACHELKE, J. F. R.; BOTOMÉ, S. P. Comportamento de vestibulandos em relação à organização, gerenciamento e alocação do estudo em períodos de tempo. Interação em Psicologia, v. 8, n. 2, p. 271-286, 2004. 
ZANON, D. P.; ALTHAUS, M. M. Instrumentos de avaliação na prática pedagógica universitária. 2008. Disponível em: <http://www.maiza.com.br/>. Acesso em: 01 mai. 2016.

Recebido: 2017-02-07

DOI: $10.3895 /$ rbect.v10n3.5592

Como citar: CHAVES, B. E.; PANTOJA, L. D. M.; OLIVEIRA, R. D.; MENDES, R. M. S.; PAIXÃO, G. C. Análise de questões avaliativas de fisiologia vegetal realizadas em um ambiente virtual de aprendizagem. Revista Brasileira de Ensino de Ciência e Tecnologia, v. 11, n. 1, 2018.

Disponível em: <https://periodicos.utfpr.edu.br/rbect/article/view/5592>. Acesso em: xxx.

Correspondência: Bruno Edson Chaves - bruno.edson@uece.br Direito autoral: Este artigo está licenciado sob os termos da Licença Creative Commons-Atribuição 4.0 Internacional. 